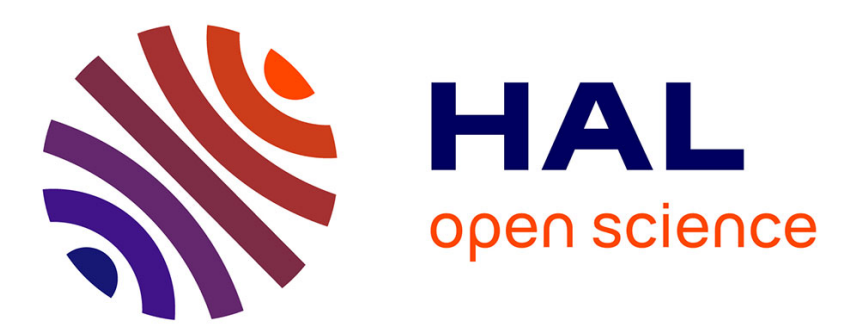

\title{
A closer look at BLEVE overpressure
}

D. Laboureur, A. M. Birk, J. M. Buchlin, P. Rambaud, L. Aprin, F. Heymes, A. Osmont

\section{To cite this version:}

D. Laboureur, A. M. Birk, J. M. Buchlin, P. Rambaud, L. Aprin, et al.. A closer look at BLEVE overpressure. PROCESS SAFETY AND ENVIRONMENTAL PROTECTION, 2015, 95, pp.159-171. 10.1016/j.psep.2015.03.004 . hal-02914194

\section{HAL Id: hal-02914194 https://hal.science/hal-02914194}

Submitted on 8 Jun 2021

HAL is a multi-disciplinary open access archive for the deposit and dissemination of scientific research documents, whether they are published or not. The documents may come from teaching and research institutions in France or abroad, or from public or private research centers.
L'archive ouverte pluridisciplinaire HAL, est destinée au dépôt et à la diffusion de documents scientifiques de niveau recherche, publiés ou non, émanant des établissements d'enseignement et de recherche français ou étrangers, des laboratoires publics ou privés. 


\title{
A closer look at BLEVE overpressure
}

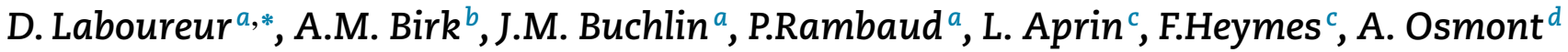 \\ a von Karman Institute, Environmental and Applied Fluid Dynamics Department, 72, Chaussée de Waterloo, B1640 Rhode-St-Genèse, \\ Belgium \\ $\mathrm{b}$ Department of Mechanical and Materials Engineering, Queen's University, Kingston, Ontario, Canada \\ c Ecole des Mines d'Alès, Laboratoire Génie de l'Environnement Industriel, Alès, France \\ d CEA, DAM, GRAMAT, F-46500 Gramat, France
}

\begin{abstract}
A B S T R A C T
The overpressure produced by the boiling liquid expanding vapor explosion (BLEVE) is still not well understood. Various methods have been published on the overpressure modeling in the far field. They mostly differ by the modeling of the expansion energy, used to scale the distance to the source where the overpressure needs to be calculated. But these meth-ods usually include a experimentally fitted reduction factor, and are mostly overestimating the overpressures. Today there is a growing interest in modeling the BLEVE overpressure in the near field, for studying the blast effect on critical infrastructure such as bridges and buildings. This requires a much better understanding of the BLEVE blast. This paper goes deeper in the understanding of the physical phenomenon leading to the BLEVE blast wave generation and propagation. First, mid-scale BLEVE experiments in addition to new exper-imental data for near field blast from a small scale supercritical BLEVE are analyzed. And second, an analysis method of the shocks observed in the experiments is presented based on fundamental gas dynamics, and allows the elaboration of a new modeling approach for BLEVE overpressure, based on the calculation of the initial overpressure and radius of the blast.
\end{abstract}

Keywords:

BLEVE

Blast wave

Overpressure

Modeling

Moving shock

Stationary shock

\section{Introduction}

The boiling liquid expanding vapor explosion (BLEVE) has been a topic of research since the early 1960s. Research has provided us with some simple practical methods to estimate the consequences of these events, resumed in guidelines like the CCPS (1994) or the TNO (1997), but also methods of reducing the likelihood of BLEVE events (Abbasi and Abbasi, 2007). Unfortunately, BLEVE still happen nowadays and the description of the physical aspects of the phenomenon is still not clear. In addition, today studies are underway looking into the effects of accidental or intentionally staged events on critical infrastructure, which requires a more detailed description of BLEVE hazards, and especially at very close range.

This article focus on one specific hazard of BLEVE: the blast wave. The objectives are to better understand the generation and the propagation of the blast, and to propose a new modeling approach based on fundamental gas dynamics and thermodynamic principles.

In most of the publications, blast modeling is dedicated to the prediction of the first peak amplitude, and this overpressure peak is modeled using generalized methods, based on thermodynamic equations. The procedure first consists in the calculation of the expansion energy, which is expressed

\footnotetext{
* Corresponding author.

E-mail address: laboureu@vki.ac.be (D. Laboureur).

URL: http://www.vki.ac.be (D. Laboureur).
} 
differently depending on the model. But all the models include the expansion energy in the calculation of a scaled distance that is used to evaluate the overpressure from scaled overpressure curves (CCPS, 1994). In another approach, van den Berg published new scaled overpressure curves (van den Berg, 2008) from a modeling of expansion controlled shock production, based on the assumption that the explosive evaporation of the liquid is as fast as the inertia of the expanding mixture (van den Berg et al., 2004, 2006).

In parallel to the modeling research, BLEVE experiments have been conducted over the years, and included a variety of fluids, vessel shape and scale, heating system, and intrumentation (Birk et al., 2006a,b; Birk and Vandersteen, 2006; Balke et al., 1999; Davison and Edwards, 2008; Giesbrecht et al., 1981; McDevitt et al., 1988, 1990; Johnson et al., 1991; Stawczyk, 2003; Rirksomboon, 1997; van der Voort et al., 2012, 2013). An experimental database of BLEVE overpressure measurements is very important to validate overpressure models, and especially in the near field. But the number of BLEVE experiments that measured the overpressure signals remains to scarce, and the current overpressure models do not allow the complete understanding of the physics behind the BLEVE blast effects (Laboureur et al., 2013). It is usually stated that the blast effect comes from the expanding vapor driving the ambient air like a piston, assuming that the liquid cannot do work on the surroundings as the liquid must flash to vapor to do expansion work. But with the case of a tank filled only with liquid there is no vapor space, and therefore the blast effect must come from phase change. When there is a vapor space then there is vapor available immediately to produce a blast effect. Does this vapor produce the blast or does the flashing liquid also contribute? Can they both produce a blast wave?

In this paper we have attempted to predict the blast effect from selected tests series using fundamental fluid and thermodynamic principles only, trying to avoid any fitting parameter (Genova et al., 2008; Casal, 2008) or numerical modeling (van den Berg et al., 2004, 2006). In addition to the mid-scale experiments performed by Birk and Vandersteen (2006), a key new data set from Laboureur is used (Laboureur, 2012), as the blast effect has been measured above the reservoir in addition to the usual side overpressure measurements.

First, Section 2 describes the two types of experiments performed by the authors, and Section 3 describes the modeling of both a stationary shock or a moving shock, based on thermodynamic and gas dynamic assumptions. Then the modeling of the moving shock is used to develop a new approach to model the first peak overpressure generated by a BLEVE as described in Section 4, together with a summary of the experimental data used for comparison with the proposed models discussed in Section 5.

\section{BLEVE blast wave analysis based on experimental results}

\subsection{BLEVE of $1.9 \mathrm{~m}^{3}$ propane tank}

Between 2001 and 2002, a series of BLEVE experiments were performed with a $1.9 \mathrm{~m}^{3}$ propane tank (Birk and Vandersteen, 2006). Internal pressure, temperature at different positions inside the reservoir, and overpressures at $10-40 \mathrm{~m}$ both at side and end directions from the reservoir have been measured. Concerning the experiments used in this paper, the reservoir was heated by an array of gas burners, and a pressure relief valve was connected to the reservoir, and set to $1.72 \mathrm{MPa}$. Among the nine BLEVE recorded, the strongest happened after the reservoir failure at 1.9 MPa, and was filled about half with saturated propane liquid and half with saturated vapor at the instant of failure. The Fig. 1 illustrates the rupture of the reservoir, showing two distinct steps. The initial frames show a growing lobe of fire as the failure grows along the length of the vessel. But the vessel does not directly fail catastrophically, and the fire observed in the first three frames is a propane jet from the rupture opening. After the third frame, the vessel fails catastrophically and the propane expands explosively out of the vessel. The shock wave is not visible on these pictures, but it can be guessed as the last image in the sequence shows a condensation cloud produced by the shock passing through the moist atmosphere. The shock is buried in the cloud in the 4th frame and emerges out of the propane cloud in the last frame. Even if the shock is not visible, comparison with the results of Laboureur can lead to the assumption that the shock is created at a certain distance from the tank surface when the tank fully opens.

The size of this cloud can be estimated by assuming that the isentropic expansion energy goes entirely into pushing the atmosphere out of the way. The cloud radius can be calculated from the Eq. (1). In this equation, $E_{\text {is }}$ is the isentropic expansion energy (defined as the difference in internal energies evaluated before rupture $\left(u_{\mathrm{i}}\right)$ and after expansion to the atmospheric pressure $\left.\left(u_{\mathrm{f}}\right): E_{\mathrm{is}}=m\left(u_{\mathrm{i}}-u_{\mathrm{f}}\right)\right)$ and $P_{\text {atm }}$ is the ambient pressure. In this case $E_{i s}=32 \mathrm{MJ}$, which gives an $R_{\mathrm{C}}=4.3 \mathrm{~m}$. This correlates well with the images of Fig. 1 as the length of the reservoir is equal to $2.7 \mathrm{~m}$.

$$
\frac{4}{3} \pi R_{\mathrm{c}}^{3}=\frac{E_{\text {is }}}{P_{\text {atm }}}
$$

Looking closer at the first step of the BLEVE, a stationary shock can be observed above the opening of the vessel, as shown in Fig. 2. This shock is initially a semicircular arc originating from the tips of the failure crack. As the crack grows this arc grows with it. When the flow is dry vapor the flow before the shock is clear and condensation takes place after the shock. When liquid is entrained into the flow then we see the white cloud in the middle of the jet before the shock. When the vessel fails catastrophically and opens fully, the standing shock is released and travels into the ambient atmosphere.

The second step, once the reservoir has failed catastrophically, produced the blast waves shown in Figs. 3 and 4. These figures show the classic overpressure waveform expected from a BLEVE where both liquid and vapor are present at the instant of failure. In Fig. 3 left, the overpressure measured at $10 \mathrm{~m}$ from the side of the vessel shows a first overpressure peak, followed by an underpressure of similar magnitude to the overpressure, caused by an overexpansion of the vapor flow. The underpressure is then followed by a second overpressure from the recovery of the vapor flow. A third overpressure is also observed afterwards, and believed to be caused by the flashing liquid. None of these are strong shocks since they are all moving only slightly above sonic velocity. In Fig. 3 right, we see these same shocks but recorded at $20 \mathrm{~m}$ from the tank side. The shock fronts are a little steeper and the overpressures peaks have decayed. An underpressure is also developing behind the second wave. Notice that the third wave has steepened.

In Fig. 4 left, the overpressures have decayed further at $30 \mathrm{~m}$. It looks like the third wave has caught up and merged 


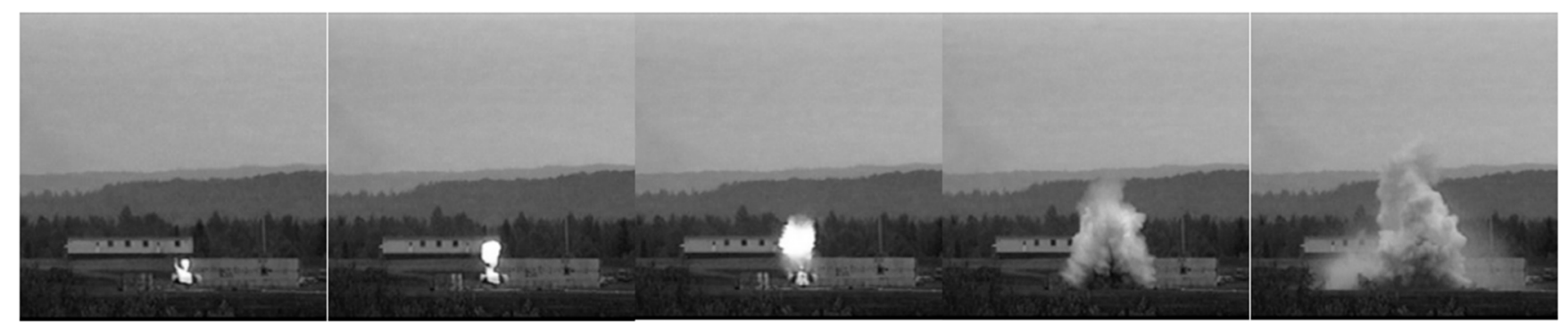

Fig. 1 - BLEVE of $1.9 \mathrm{~m}^{3}$ propane tank, 50\% full of liquid, failure pressure $2 \mathrm{MPa}$ ( $\Delta \mathrm{t}$ between frames: $33 \mathrm{~ms}$ ).

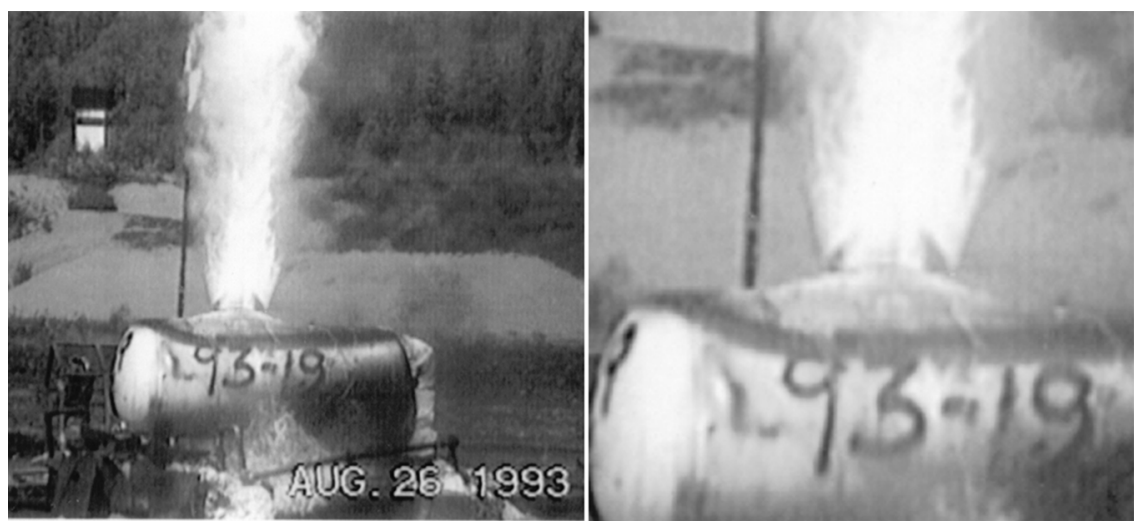

Fig. 2 - Typical view of two-step BLEVE where failure begins as a small opening in a fire weakened wall. Two phase propane jet visible.
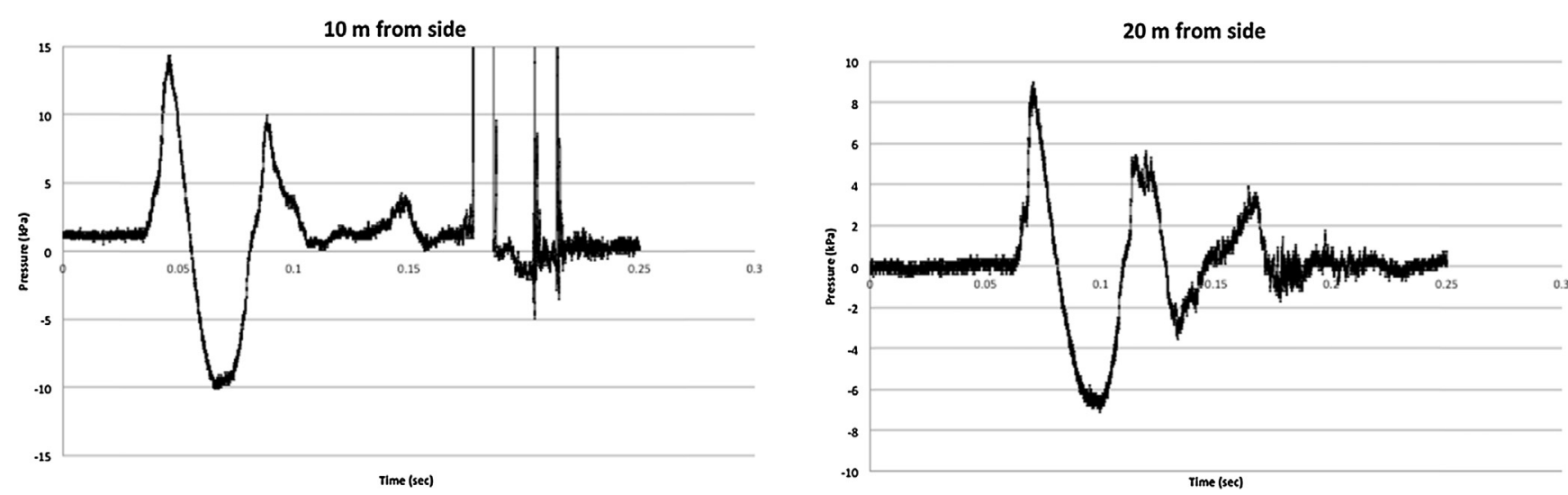

Fig. 3 - Overpressure measured at $10 \mathrm{~m}$ (left) and $20 \mathrm{~m}$ (right) from side of $1.9 \mathrm{~m}^{3}$ propane tank.
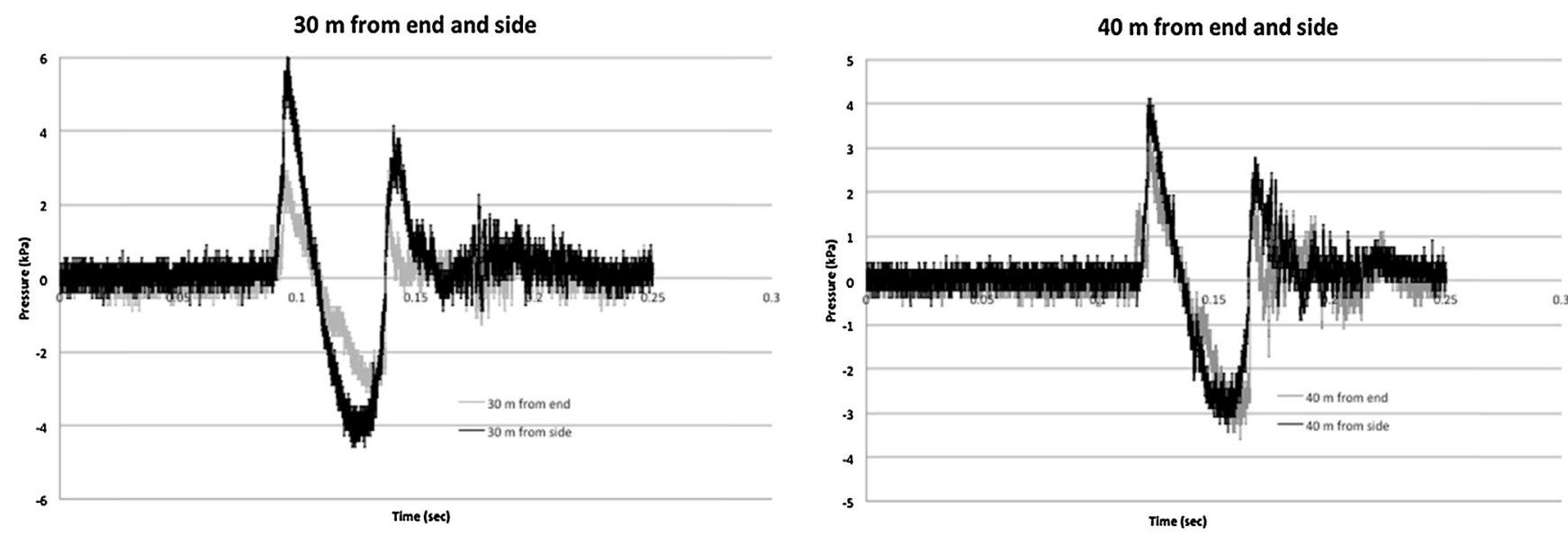

Fig. 4 - Overpressure measured at $30 \mathrm{~m}$ (left) and $40 \mathrm{~m}$ (right) of $1.9 \mathrm{~m}^{3}$ propane tank. 


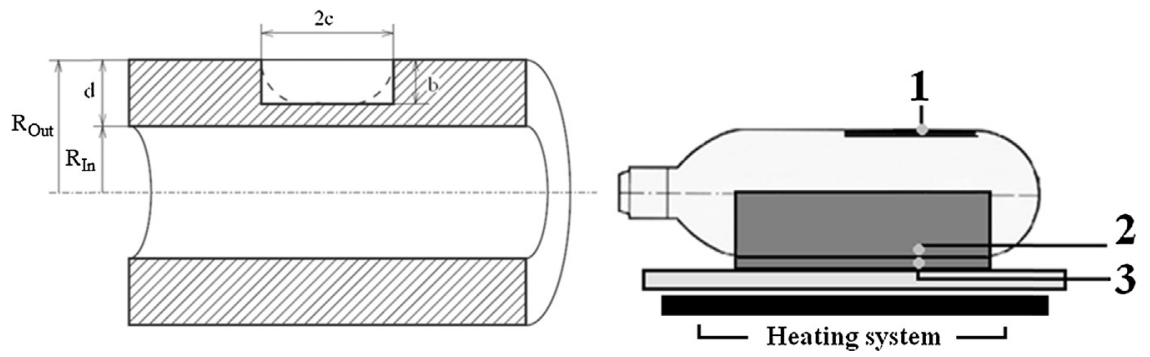

Fig. 5 - Left: Reservoir dimensions nomenclature. Right: Reservoir configuration and position of temperature measurement points.

with the second wave thereby helping the second wave to almost maintain the $20 \mathrm{~m}$ location overpressure value. This figure also shows data measured from the tank end (in grey in Fig. 4). The overpressure from the end is lower than that from the sides, and can be explained by shielding from the ends as the tank opened. The Fig. 4 right shows the data at $40 \mathrm{~m}$ distance. At this point the overpressures have decayed further and the end and side pressures have almost the same amplitude.

\subsection{Catastrophic failure of $95 \mathrm{ml}$ vessel filled with supercritical fluid}

Small scale experiments were recently completed by Laboureur that studied the detailed failure mechanisms of very small cylinders $(95 \mathrm{ml})$ filled entirely with propane, containing $86 \%$ of liquid at ambient temperature (Laboureur, 2012). The experiments were performed inside a dedicated safe facility called Bleve And Boilover ExperimentaL setup (BABELs). The facility consists of a cylindrical chamber of $2 \mathrm{~m}$ diameter, and $3 \mathrm{~m}$ height, made out of steel, with roundshaped flanges, three series of seven optical accesses of $0.15 \mathrm{~m}$ in diameter, and an elliptical door.

The cylinders were electrically heated from the bottom until rupture at pressures between 20 and $45 \mathrm{MPa}$ were supercritical BLEVE were observed. The temperature was measured in the upper part of the reservoir (position 1 in Fig. 5 right) and in the lower part (position 2 in Fig. 5 right). To ensure an early and reproducible failure, the cylinders were mechanically machined with an axial defect along the length of the reservoir and located on top of the reservoir. The cylinder and defect characteristics are given in Table 1: $d$ and $b$ being determined by the tool used to machine the defect, and $2 c$ being varied from $10 \mathrm{~mm}$ to the longest possible according to the size of the reservoir. Overpressure has been measured above the reservoir at $0.28 \mathrm{~m}$, and at ground level along the reservoir, at 0.5 , 0.6 , and $0.7 \mathrm{~m}$. High-speed visualization and shadowgraphy were also used. More information about the BABELs facility and the experimental setup are provided by Laboureur (2012).

From the experiments of Laboureur, the sequences of images, illustrated in Figs. 7 and 8, show the initial release of the propane. Both cylinders failed at a fluid pressure and temperature that are supercritical. The white cloud observed can be described as condensation of the supercritical fluid into vapor and liquid droplets. The Fig. 7 shows a lower pressure

\section{Table 1 - Summary of cylinder geometry.}

\begin{tabular}{lcccccc} 
Fluid & $m(\mathrm{~g})$ & $\mathrm{V}(\mathrm{ml})$ & $R_{\text {out }}(\mathrm{mm})$ & $d(\mathrm{~mm})$ & $2 \mathrm{c}(\mathrm{mm})$ & $b(\mathrm{~mm})$ \\
\hline Propane & 41 & 95 & 40 & 2 & $10,15,80$ & 0.8 \\
\hline
\end{tabular}

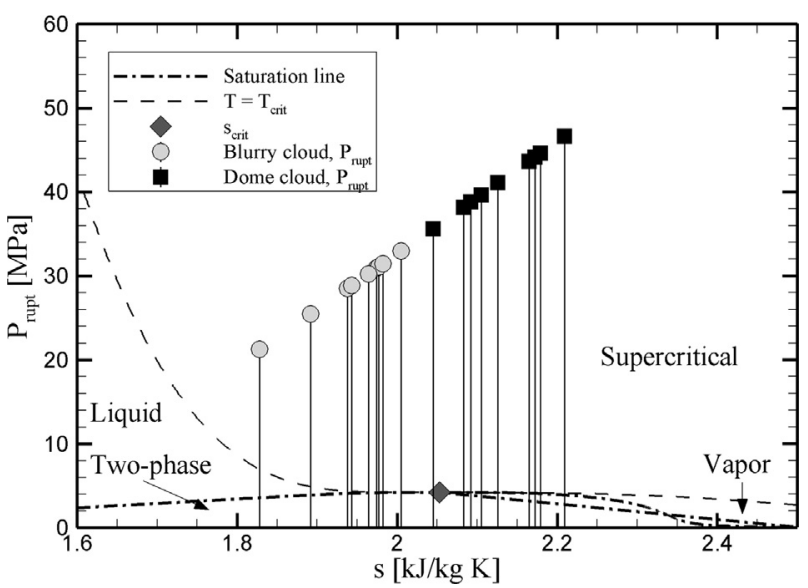

Fig. 6 - P-s thermodynamic diagram, summarizing the tests performed by Laboureur.

release with a rough cloud shape (blurry cloud) while Fig. 8 shows a higher pressure release with a very smooth cloud surface (dome cloud). The higher pressure release would have crossed the saturation line on the vapor side of the dome and the lower pressure failure would have crossed on the liquid side, as observed in Fig. 6 . The cloud stops growing when the expansion energy is used by moving the ambient air out of the way. The cloud then quickly disperses. The volume of the cloud before dispersion can be calculated from Eq. (1), as done for the experiments of Birk. In these experiments, $E_{\mathrm{is}}=7.65 \mathrm{~kJ}$, which gives an $R_{c}=0.26 \mathrm{~m}$, and correlates well with the images as the cylinder length is equal to $0.138 \mathrm{~m}$, and in Fig. 10, the cloud stabilizes around the height of the horizontal bare where the pressure transducer is fixed and located at $0.28 \mathrm{~m}$ from the reservoir. The two-step BLEVE detailed from the experiments of Birk has not been observed in this scale and with a supercritical rupture. As it can be observed in Figs. 7 and 8, once the cylinder starts its rupture, it does not stop until complete failure. Therefore, no propane jet preceded by a stationary shock has been observed.

Overpressure measurements for two groove lengths $(2 c=0.04 \mathrm{~m}$ and $2 c=0.01 \mathrm{~m})$ are showed in Fig. 9 right for an overpressure measured at taken at 0.5 and $0.6 \mathrm{~m}$ from the side of the reservoir, and in Fig. 9 left for an overpressure measured at $0.28 \mathrm{~m}$ above the reservoir. The blast wave pressure at a fixed reference distance shows a first peak (A in Fig. 9), followed by a sharp drop with negative part, which is the typical shape of a blast wave, similarly observed in the measurements of Birk. The value of the overpressure peak also increases when the groove length decreases, or in other words, when the rupture pressure increases.

On the pressure signal measured above the reservoir, a second peak is observed ( $C$ in Fig. 9 left) for small groove lengths. 

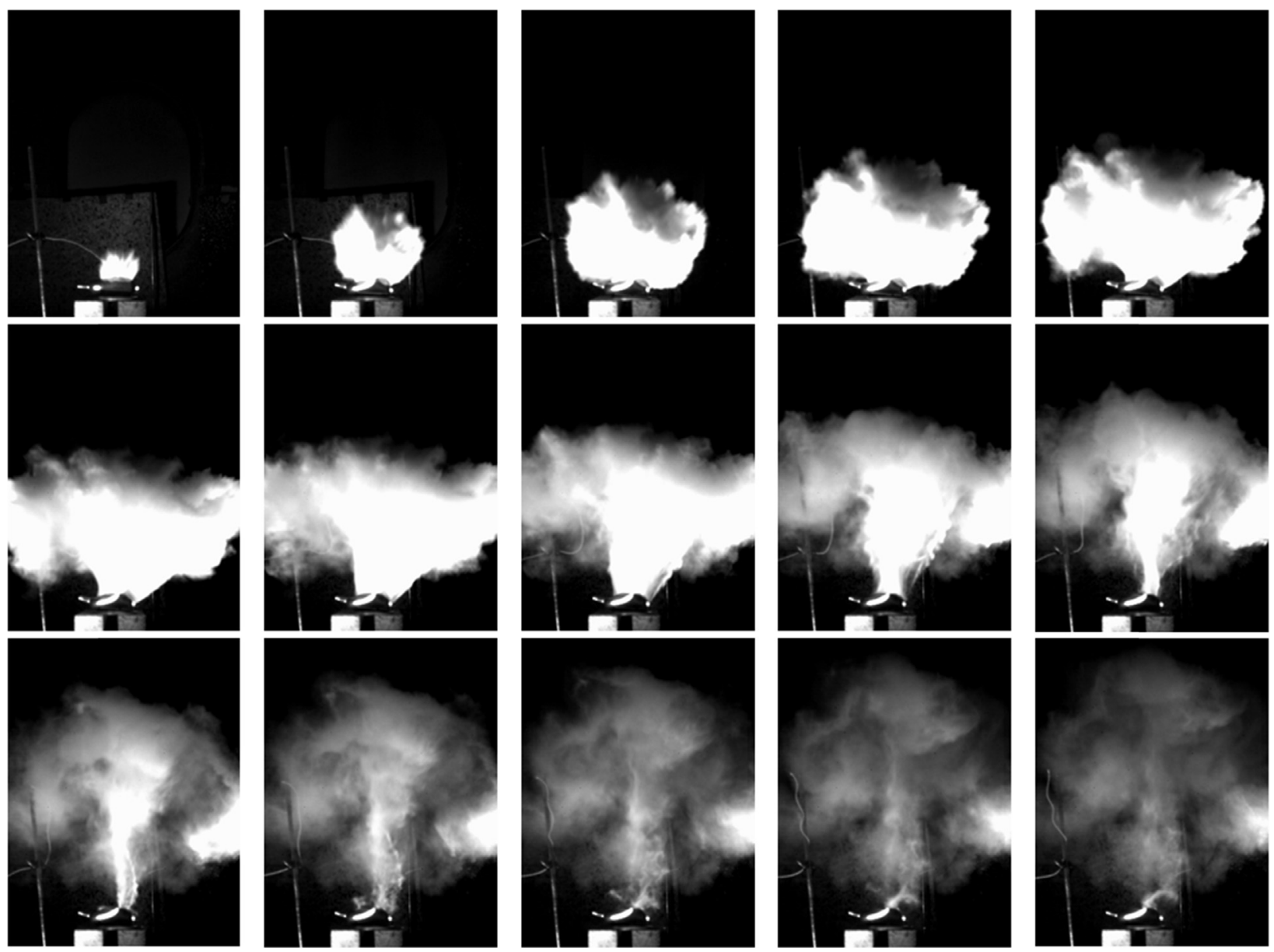

Fig. 7 - NTG cylinder, $2 c=0.077 \mathrm{~m}$ (rupture pressure: $35 \mathrm{MPa}$ ), no smooth dome $(\Delta \mathrm{t}=0.28 \mathrm{~ms}$ ).

This peak corresponds to the moment when the dome-like cloud touches the pressure sensor (which is located in the horizontal bar, as observed in Fig. 10). Finally, a last peak is visible both on the shadowgraph (E in Fig. 10) and on the pressure signals (E in Fig. 9), and observed after the rupture of reservoirs with small groove lengths, corresponding to the apparition of the dome-like cloud. In the shadowgraph images (see Fig. 10), this second blast wave appears just after the cloud has disappeared, that is, evaporated. And as the dome-like cloud vaporizes a lot faster than the blurry cloud due to the higher rupture pressure and temperature and to the smaller proportion of supercritical fluid that has condensed, this fast
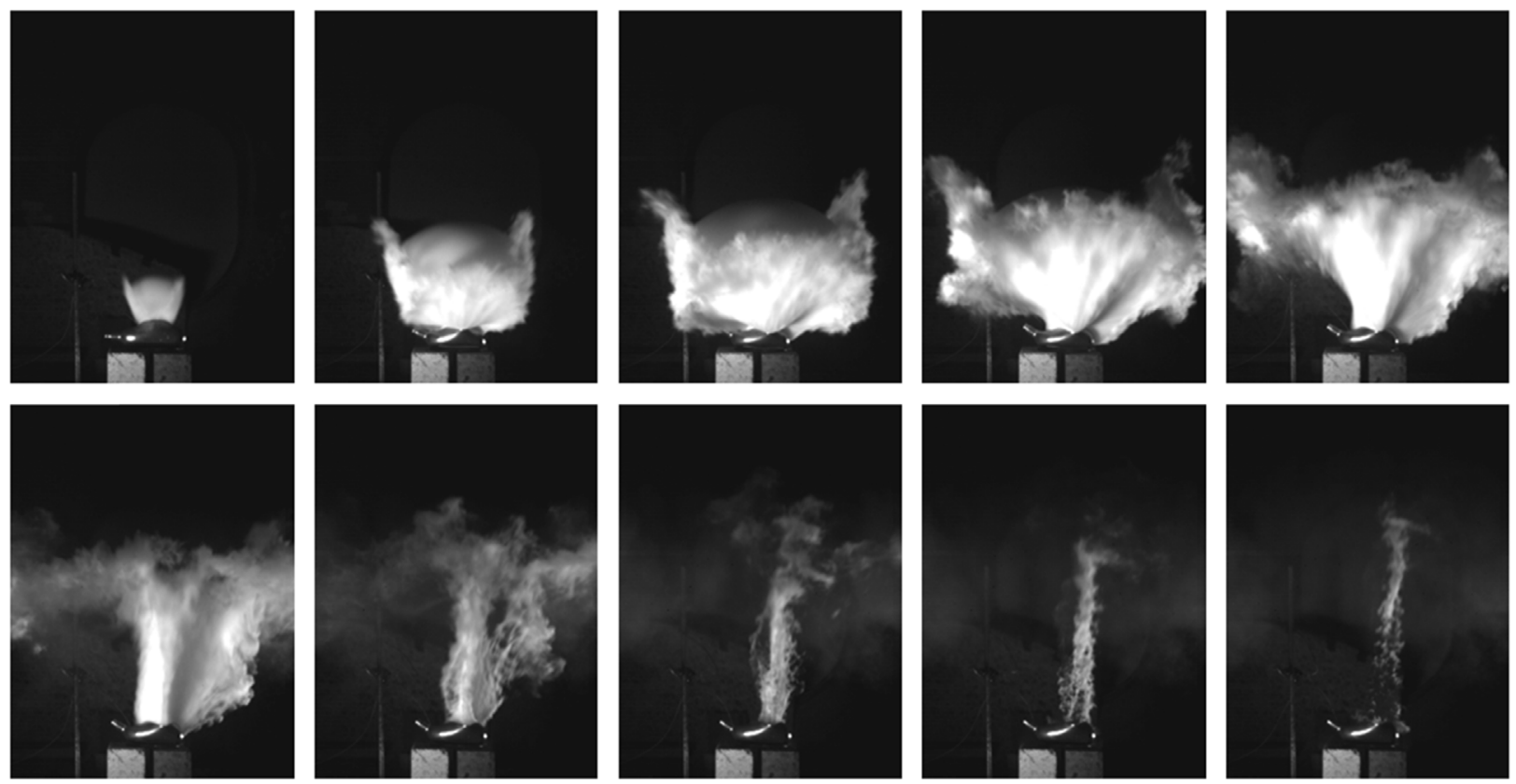

Fig. 8 - NTG Cylinder $2 c=0.015 \mathrm{~m}$, high pressure failure $(44 \mathrm{MPa})$ with smooth dome $(\Delta t=0.28 \mathrm{~ms})$. 

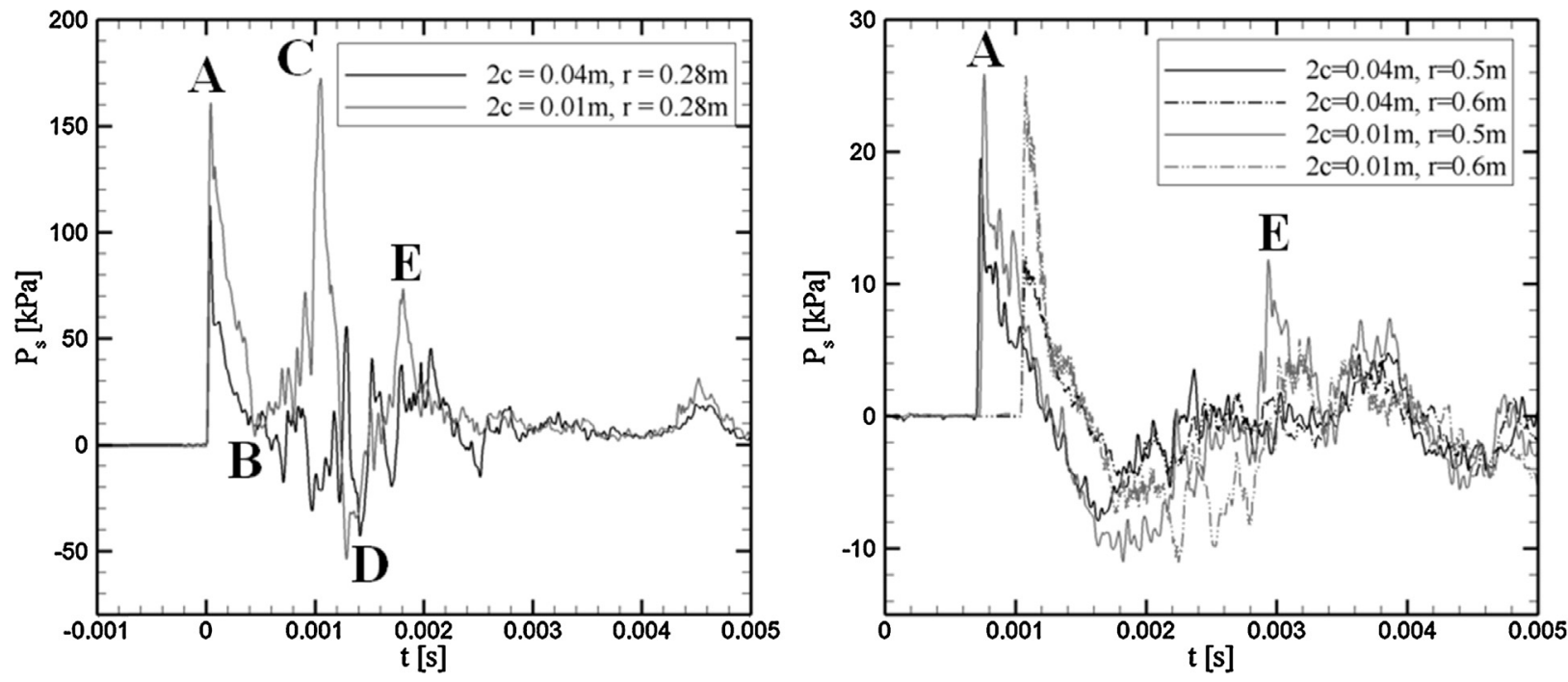

Fig. 9 - Overpressure signal. Left: above the reservoir $(0.28 \mathrm{~m})$. Right: at ground level, on the sides of the reservoir $(0.5$ and $0.6 \mathrm{~m})$.

vaporization seems to be the cause of the second blast wave generation. Finally, the time scale of the cloud ejection and the blast waves is a lot smaller for the experiments of Laboureur than for Birk. Indeed, the duration of the first positive and negative blast overpressure peaks in the measurements of Laboureur is approximately 35 times smaller than observed in the measurements of Birk.

\section{BLEVE shock modeling}

As a first modeling approach, the modeling of the different states of the fluid during the rupture will be done based on thermodynamic and gas dynamic assumptions. The modeling is divided in two parts, according to the two types of shock observed. First, the stationary shock, as observed in the experiments of Birk during the first step of a two-step BLEVE is investigated. And second, the moving shock observed both in the experiments of Birk (second step) and Laboureur is modeled.

\subsection{Stationary shock}

As observed in Fig. 2 illustrating the experiment of Birk, a stationary shock is formed where the reservoir has just ruptured (Fig. 11). At this step of the reservoir rupture, the opening can be considered as a sharp edge orifice, which experiences a sonic point beyond the exit of the orifice. To correctly model this situation, four fluid states are considered, as shown in Fig. 11.

- State 0: Before reservoir rupture, fluid at rest.

- State 1: The fluid expands isentropically to sonic conditions. Therefore, the conditions in 1 are found by iteration on $P_{1}$, such that $U_{1}$ (the fluid velocity) and $a_{1}$ (the sound velocity)
A
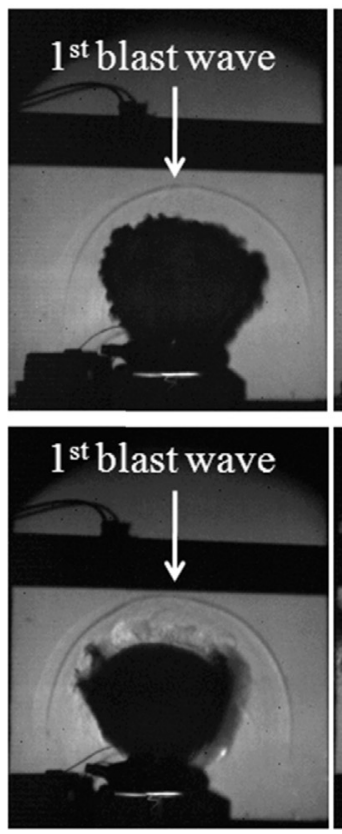

B
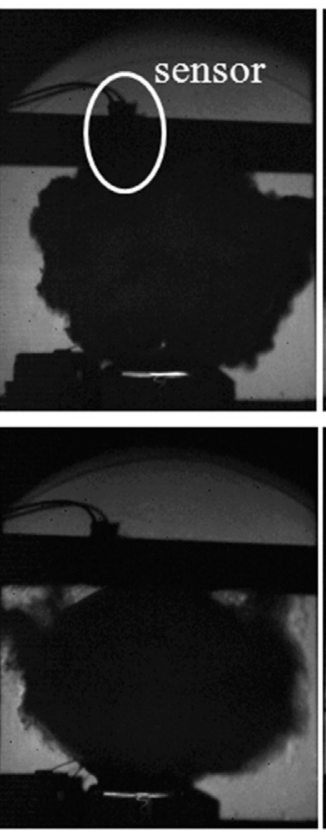

C
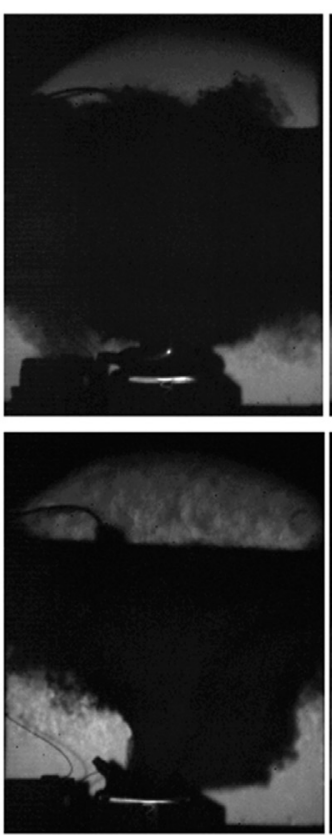

D
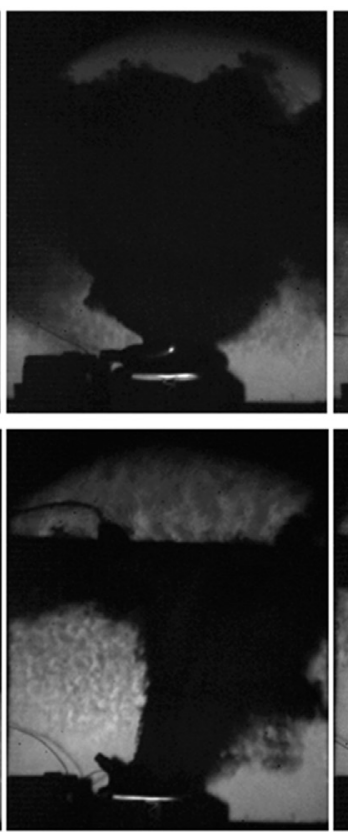

E
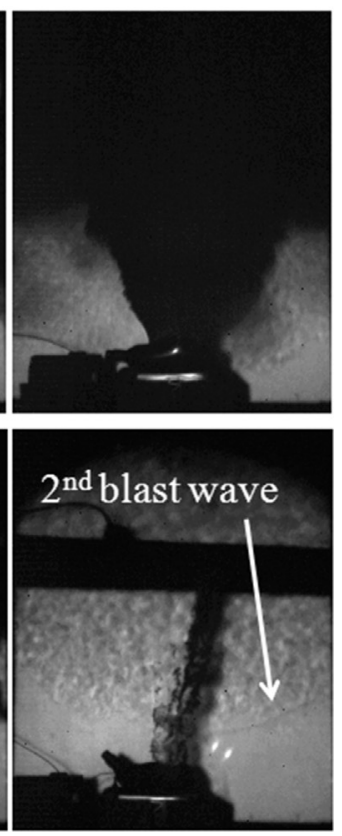

Fig. 10 - Shadowgraph visualization of cloud and blast wave at five times indicated by letters A-E in Fig. 9. 

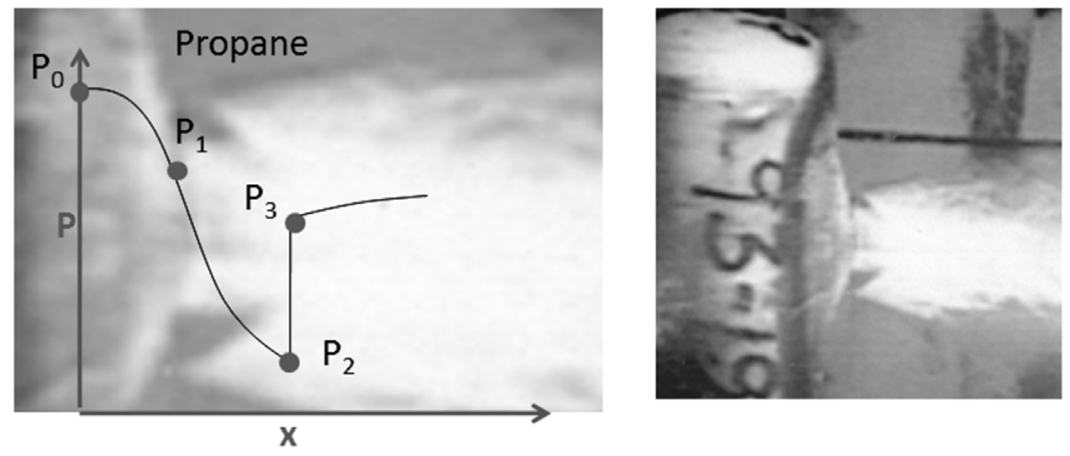

Fig. 11 - Pressure evolution and stationary shock, during first step of BLEVE observed by Birk.

$\begin{array}{ll}\text { Table } 2 \text { - Governing equations, normal shock. } \\ \text { State } & P=\rho R T \\ \text { Mass conservation } & d(\rho U)=0 \\ \text { Momentum conservation } & A d P=d\left(\rho U^{2}\right) \\ \text { Energy conservation } & d h_{0}=d\left(h_{0}+d\left(U^{2} / 2\right)\right)=0 \\ \text { At shock } & d A=0\end{array}$

are equal. The velocity $U_{1}$ is calculated assuming the conservation of the total enthalpy, and a negligible velocity at rupture. The 1D energy equation, as written in Eq. (2), can be applied (White, 1986).

$$
\frac{U_{1}^{2}}{2}=\left(h_{0}-h_{1}\right)
$$

- State 2: The fluid continues to expand until the conditions before the shock $\left(P_{2}, v_{2}, T_{2}\right)$. The velocity $U_{2}$, at $P_{2}$ is calculated analogous to Eq. (2).

- State 3: A normal stationary shock is assumed, and the pressure after the shock is equal to the atmospheric pressure $\left(P_{3}=P_{\text {atm }}\right)$.

To determine the variables in state 2 and 3, the governing equations of a normal shock need to be solved. The fluid is assumed to be an ideal gas, the shock is supposed to have a constant area, the flow is considered 1D, frictionless, adiabatic, with no external work and where body forces are negligible. Therefore, the system of equations to solve is described in Table 2, where $P$ is the pressure, $U$ is the shock velocity, $h$ is the enthalpy, $v$ is the specific volume, $\rho$ is the density and A is the flow area (White, 1986).

As the ideal gas assumption has been considered, this set of equations can be simplified, to give the pressure $\left(\mathrm{P}_{3} / \mathrm{P}_{2}\right)$ and temperature $\left(T_{3} / T_{2}\right)$ ratios across the shock, in addition to the Mach number after the shock $\left(M_{3}\right)$, if the Mach number before the shock $\left(M_{2}\right)$ is known. This Mach number $M_{2}$ can be found by iteration on $P_{2}$, providing that $P_{3}$ is equal to the atmospheric pressure. The $k$ (defined as $C_{\mathrm{p}} / C_{\mathrm{v}}$ ) is calculated from propane at conditions of state 2 , and the sound speeds are determined in propane vapor. This set of equations is expressed in Eq. (3).

$$
\begin{aligned}
& \frac{P_{3}}{P_{2}}=\frac{1}{k+1}\left[2 k M_{2}^{2}-(k-1)\right] \\
& \frac{T_{3}}{T_{2}}=\left[(k-1) M_{2}^{2}+2\right] \frac{2 k M_{2}^{2}-(k-1)}{(k+1)^{2} M_{2}^{2}} \\
& M_{3}^{2}=\frac{(k-1) M_{2}^{2}+2}{2 k M_{2}^{2}-(k-1)}
\end{aligned}
$$

\begin{tabular}{|c|c|c|c|c|}
\hline State & $P$ & $\mathrm{~T}\left({ }^{\circ} \mathrm{C}\right)$ & Mach & Quality \\
\hline 0 & $1.9 \mathrm{MPa}$ & 55 & 0 & 1.0 \\
\hline 1 & $1.14 \mathrm{MPa}$ & 32 & 1 & 0.98 \\
\hline 2 & $9.3 \mathrm{kPa}$ & -85 & 3.18 & 0.87 \\
\hline 3 & $101.3 \mathrm{kPa}$ & 87 & 0.4 & Superheated \\
\hline
\end{tabular}

The four fluid states as described in this model have been applied to the experiment of Birk, whose results were described in the Section 2.1. This experiment involved a vessel of $1.9 \mathrm{~m}^{3}$ filled at $50 \%$ with liquid at the moment of rupture that happened at $1.9 \mathrm{MPa}$. The calculation here only involves the vapor part, and the results are shown in Table 3.

\subsection{Moving shock}

As observed in Fig. 1 for the experiments of Birk and in Fig. 10 for the experiments of Laboureur, when the reservoir fails catastrophically, the cloud of expanding fluid acts like a piston. And at some point, the piston effect creates a shock in the air that propagates into the surrounding. To correctly model this situation, four fluid states are considered, as shown in Fig. 12.

- State 0: Before reservoir rupture, fluid at rest.

- State 1: The fluid expands isentropically, pushing the ambient air. Assuming an adiabatic process and assuming the air kinetic energy can be ignored, but the work of the fluid pushing the ambient air is taken into account. The energy conservation is expressed as Eq. (4). In addition, a guess needs to be made on $P_{1}$.

$$
-P_{1}\left(v_{1}-v_{0}\right)=u_{1}-u_{0}+\frac{U_{1}^{2}}{2}
$$

- State 2: The high velocity of the cloud expansion acts like a piston, and compress the ambient air until a pressure $P_{2}$. The calculations in this state are therefore based on air.

- State 3: A normal moving shock is assumed, and the pressure after the shock is equal to the atmospheric pressure $\left(P_{3}=P_{a t m}\right)$. Again, the calculations for this state are based on air.

The governing equations for a stationary shock can also be used for a normal moving shock, by adapting the choice of the control volume that moves at the shock speed (called $C$ ). This simplification does not affect the thermodynamic properties. The shock appears then fixed from this viewpoint, and the air appears to have a shock velocity $U_{3}=C$ on the left and $U_{2}=C-U_{1}$ on the right where $U_{1}$ is the piston velocity calculated from Eq. (2). This gives the normal shock conditions 

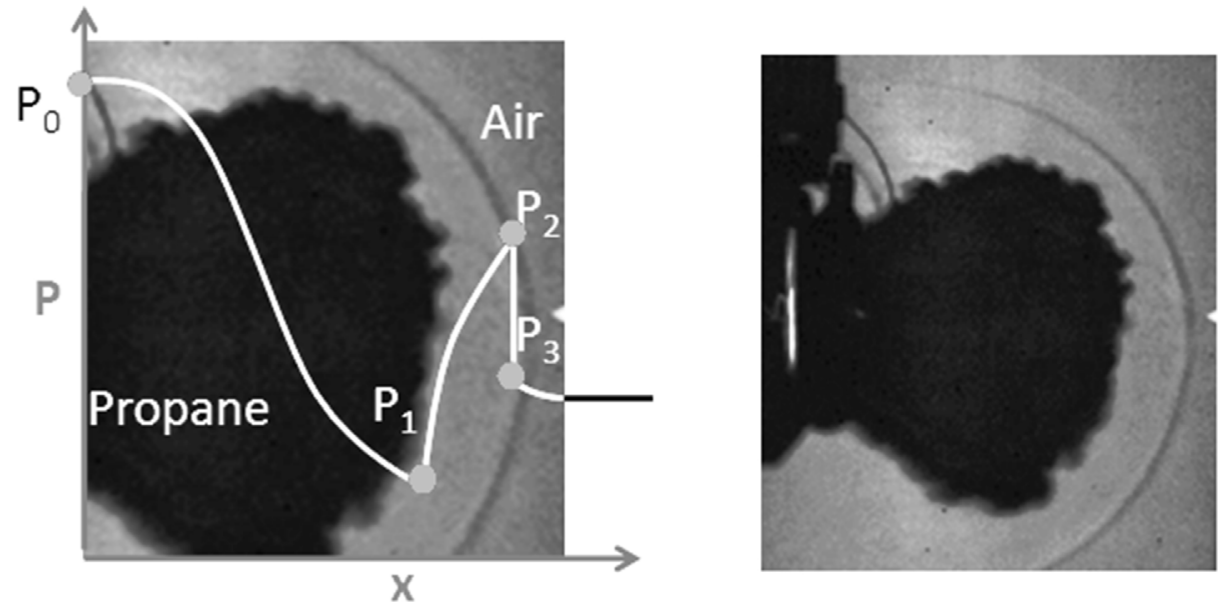

Fig. 12 - Pressure evolution and moving shock.

\begin{tabular}{|c|c|c|c|c|}
\hline State & $P$ & $\mathrm{~T}\left({ }^{\circ} \mathrm{C}\right)$ & Velocity $(\mathrm{m} / \mathrm{s})$ & Fluid \\
\hline 0 & $44.7 \mathrm{MPa}$ & 183 & 0 & Propane \\
\hline 1 & $30 \mathrm{kPa}$ & -66 & 482 (piston) & Propane \\
\hline 2 & $530 \mathrm{kPa}$ & 255 & 736 (shock) & Air \\
\hline 3 & $101.3 \mathrm{kPa}$ & 20 & 0 & Air \\
\hline
\end{tabular}

as shown in Fig. 13. But in the case of a moving shock, the shock speed $C$ is unknown, which makes impossible the use of simplified equations as done for the stationary shock. Therefore, the governing equations expressed in Table 2 were solved directly, using the Engineering Equation Solver software (EES software from F-Chart Software).

This model has been applied to the conditions of one experiment of Laboureur involving a $95 \mathrm{ml}$ reservoir containing $41 \mathrm{~g}$ of propane. The cylinder ruptured at $44.7 \mathrm{MPa}$ and a fluid temperature of $183^{\circ} \mathrm{C}$, which reflects a supercritical state. The only unknown in this model is the expanded pressure $P_{1}$. Therefore, Fig. 14 left shows the relationship between the piston and the shock velocity with the expanded pressure. On the other side, Fig. 14 right shows the velocity of the shock wave and the cloud boundary processed from the shadowgraph images illustrated in Fig. 10, based on the radius evolution. Even if the velocities at the very beginning of the test cannot be determined from the images, it can be interpolated that the cloud initial velocity lies between 400 and $500 \mathrm{~m} / \mathrm{s}$, which corresponds to an expanded pressure range of $20-35 \mathrm{kPa}$. But this range of expanded pressure models the shock velocity between 650 and $750 \mathrm{~m} / \mathrm{s}$, which seems very high compared to the measured values.

In addition, the different states, providing an overexpanded pressure of $30 \mathrm{kPa}$, are illustrated in Table 4.

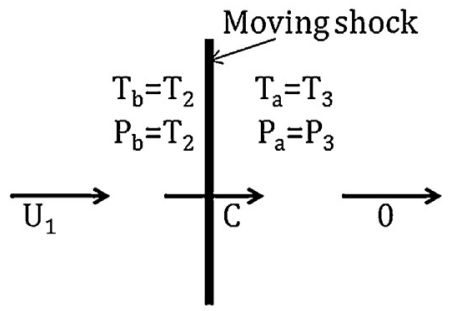

Control volume

\section{BLEVE overpressure modeling}

To be able to predict the overpressure at any distance from the source, and with more physical insight than the usual BLEVE overpressure modeling as described in CCPS (1994), the blast curves developed by van den Berg (2008) are used. van den Berg studied numerically expansion controlled overpressures from BLEVEs. In these numerical simulations, van den Berg assumes that the tank opens instantaneously and the release is hemispherical, suggesting these assumptions as a safe way to predict BLEVE blast. In addition, van den Berg assumed that the expanding vapor is saturated at the liquid temperature $\left(x_{0}=1\right)$, that is, the vapor separates from the flashing liquid. In the 1D simulation using an Euler code, the creation of the shock happens very close to the cylinder surface, from a source area covering the initial liquid volume. The decay of the overpressure then follows from this starting overpressure with a $1 / R^{n}$ relationship, as observed in Fig. 15 left.

The curves of van den Berg can be scaled with the initial shock overpressure $\Delta \mathrm{P}_{\mathrm{s} 0}$ and the initial position of the shock $R_{\mathrm{s} 0}$, using the Eq. (5), so that the function equals $(1,1)$ at $\left(\Delta P_{\mathrm{s} 0}\right.$, $R_{s 0}$ ), and decreases with an exponent $n$ as the distance from the source increases. The coefficient $n$, fitted for the propane decay curves of van den Berg, was found equal to $n=1.12$, as observed in Fig. 15 right. The coefficient for butane decay curves was found equal to $n=1.08$. But $n=1$ fits also very well the curves, but considering only $R / R_{\mathrm{s} 0}$ ratio below 10 .

$$
\begin{aligned}
& \frac{\Delta \mathrm{P}}{\mathrm{P}_{\mathrm{atm}}}=f\left(\frac{R}{m_{\mathrm{liq}}^{1 / 3}}\right) \rightarrow \frac{\Delta \mathrm{P} / \mathrm{P}_{\mathrm{atm}}}{\Delta \mathrm{P}_{\mathrm{s} 0} / \mathrm{P}_{\mathrm{atm}}}=f\left(\frac{\mathrm{R} / \mathrm{m}_{\mathrm{liq}}^{1 / 3}}{R_{\mathrm{s} 0} / \mathrm{m}_{\mathrm{liq}}^{1 / 3}}\right) \\
& \rightarrow \frac{\Delta \mathrm{P}}{\Delta \mathrm{P}_{\mathrm{s} 0}}=f\left(\frac{R}{R_{\mathrm{s} 0}}\right)
\end{aligned}
$$

Fig. 13 - From moving to stationary shock formulation. 

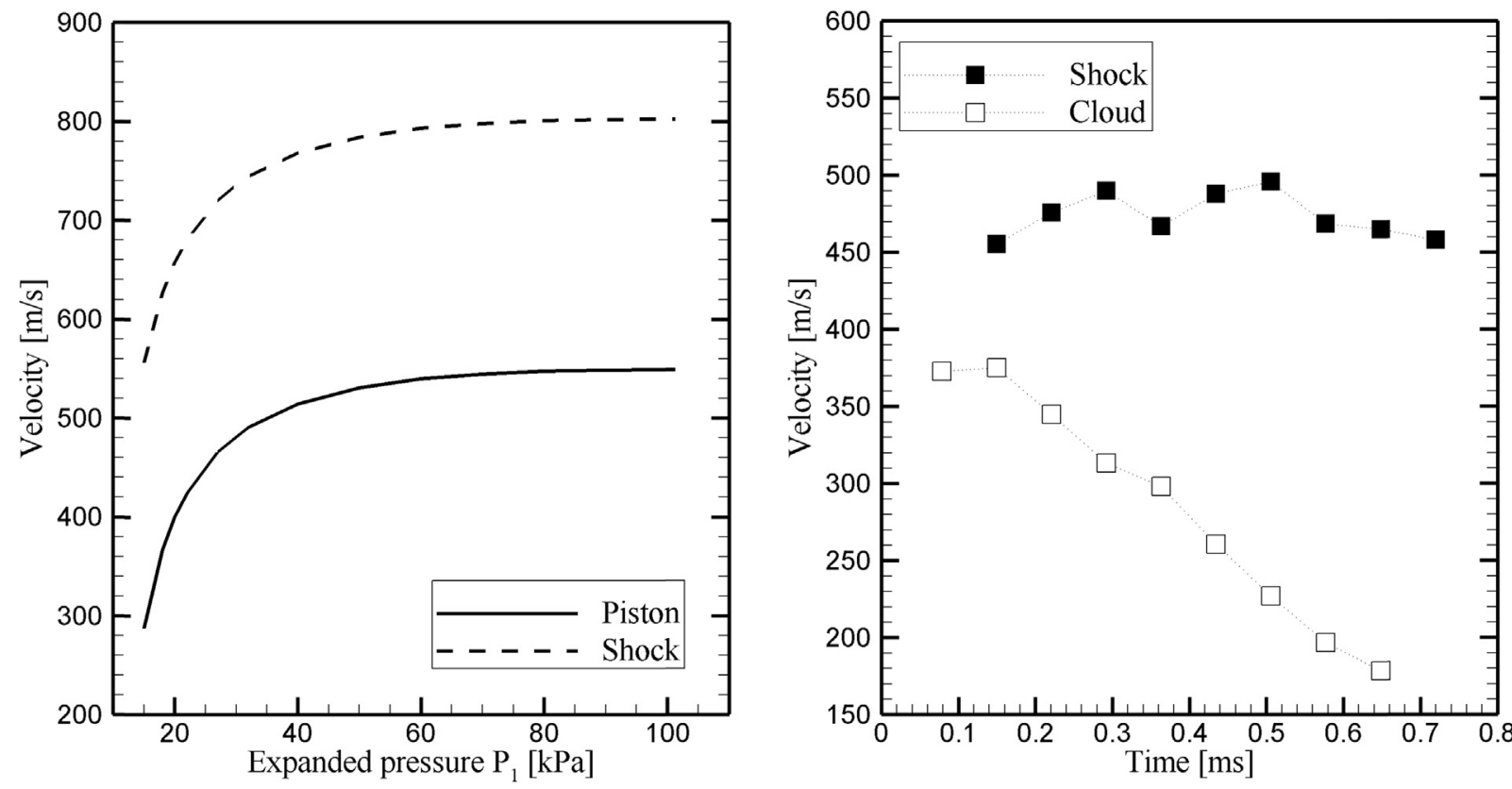

Fig. 14 - Expansion of Laboureur experiments $\left(P_{0}=44.7 \mathrm{MPa}\right)$. Left: piston and shock velocity modeled, in function of the expanded pressure $P_{1}$. Right: Cloud and shock velocity measured.

Therefore, to be able to use the blast curves of van den Berg in their scaled form, the initial overpressure generated by the shock and the initial position of this shock need to be predicted. Notice that the actual overpressure will not be uniform around the vessel because of the way the vessel opens, which cannot be predicted by the curves of van den Berg. If the vessel splits at the top, the release is expected to be more powerful straight up and less powerful at the sides and ends, as observed in Figs. 4 and 9. The release will also depend on if the vessel moves or of it is held stationary.

\subsection{Starting shock overpressure modeling}

In this model, the starting shock overpressure is the overpressure as calculated by the modeling explained in Section 3.2 , in case of a moving shock. As shown in the model, this starting overpressure then depends the pressure to which the vapor is expanded (i.e., $P_{1}$ and $v_{1}$ ), and on the piston velocity, calculated from an isentropic expansion from the initial to the expanded conditions.

$\Delta \mathrm{P}_{\mathrm{s} 0}=\mathrm{P}_{2}-\mathrm{P}_{3}$

\subsection{Starting shock position modeling}

Assuming a spherical expansion, the position of this starting shock can be approximated from the size of the expanded volume as in Eq. (7), where $m$ is the mass of the vapor source that produces the shock.

$m \frac{\left(v_{2}+v_{0}\right)}{2}=\frac{4}{3} \pi R_{\mathrm{s} 0}^{3}$

As for the piston velocity, this starting position then depends on the source of the vapor (i.e., $P_{0}, v_{0}$ ) and the pressure to which the vapor is expanded to before the shock is formed (i.e., $P_{2}, v_{2}$ ). If the Eq. (7) is applied to the experiment
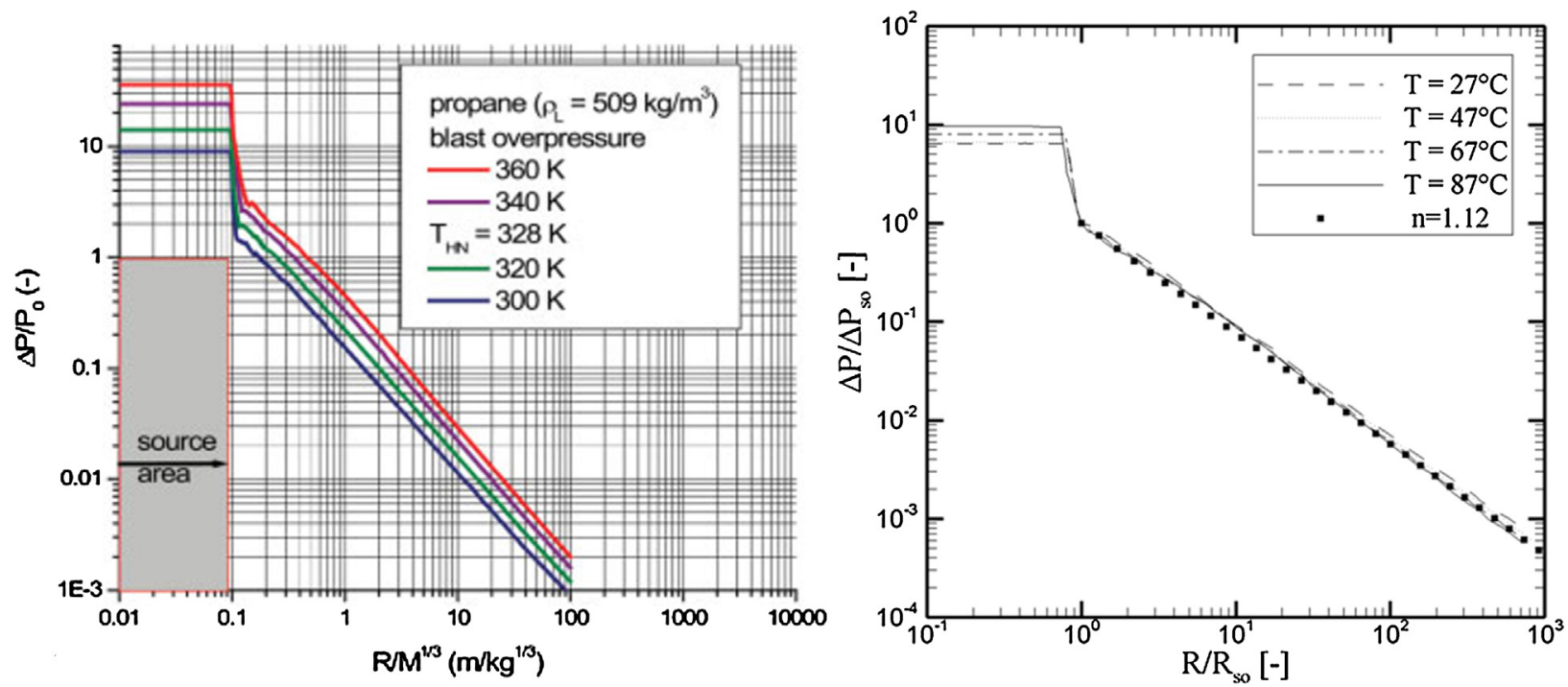

Fig. 15 - van den Berg simulations for propane. Left: Initial curves (van den Berg, 2008). Right: Scaled curves. 
of Laboureur, as presented in Section $3.1\left(P_{0}=44.7 \mathrm{MPa}\right)$, the shock is visible at first from the shadowgraph images approximately at $0.11 \mathrm{~m}$ from the center of the cylinder. The model, if the fluid overexpands to $30 \mathrm{kPa}$ gives a position of $0.17 \mathrm{~m}$, and if the fluid expands only to $101.3 \mathrm{kPa}$, the modeled position decreases to $0.12 \mathrm{~m}$ from the center of the cylinder.

\subsection{Selected experimental data}

Published BLEVE blast data is very limited. In almost every publication, data is recorded on the ground at given distances from the reservoir side or end. But there is almost no data on the location and strength of the starting shock, neither from the tank top. In addition, the uncertainties about failure conditions and the differences in the failure mechanisms make their comparison complicated. The source of the energy that generates the shock is still not clear, especially because in many experiments, the measured overpressure lies below the expected value based on energy considerations, probably as a part of this energy is lost in the opening of the reservoir. Therefore, only the most powerful BLEVEs observed will be investigated here. Five different sets of data are discussed in this paper. They have been selected because they cover a large range of scales and they show some of the highest BLEVE overpressures recorded. At first, the experiments of Laboureur and Birk, as described in Section 2 are used. In addition, the test of Giesbrecht et al. (1981) that involved a $1 \mathrm{~m}^{3}$ vessel with $452 \mathrm{~kg}$ of liquid propylene (already used by van den Berg for comparison of his model (van den Berg et al., 2004)), and the blast from a full scale tank car test performed by the BAM are also used (Balke et al., 1999). Finally, the last set of experiments comes from a $5.7 \mathrm{~m}^{3}$ test with propane or butane, performed by British gas (Johnson et al., 1991).

The Table 6 gives a summary of the data considered. If several tests were performed, only the one that caused the stronger overpressure is presented in the table. For each test, the overpressure measured the closest from the reservoir is mentioned $\left(\Delta \mathrm{P}_{\mathrm{a}}\right.$, measured at a distance $\left.\mathrm{R}_{\mathrm{a}}\right)$. In addition, this value is compared with the overpressure predicted from the blast curves of van den Berg $\left(\triangle \mathrm{P}_{\mathrm{VDB}}\right)$ if published, as van den Berg did not calculate a BLEVE from propylene, or from supercritical fluids. Then, the initial overpressure is calculated from Eq. (8).

$$
\frac{\Delta \mathrm{P}}{\Delta \mathrm{P}_{\mathrm{s} 0}}=\left(\frac{\mathrm{R}}{R_{\mathrm{s} 0}}\right)^{n} \rightarrow \Delta \mathrm{P}_{\mathrm{s} 0}=\frac{\Delta \mathrm{P}_{\mathrm{a}}}{\left(R_{\mathrm{a}} / R_{\mathrm{s} 0}\right)^{n}}
$$

In this equation, the measured value and distance $\Delta P_{\mathrm{a}}$ and $R_{a}$ are used. The initial shock position is taken as five times the cylinder radius. Indeed, in the measurements of Laboureur as shown before, the shock appeared at $0.1 \mathrm{~m}$, which is five times the cylinder radius. As this is the only position measured, it will be assumed that all reservoirs experience a similar position ratio. Therefore, $R_{\mathrm{S} 0}=5(D / 2)$. From Eq. (8), $\Delta P_{\mathrm{S} 0}$ can easily be calculated, using $n=1.12$ for propane, and $n=1.08$ for butane. Finally, this initial overpressure is scaled back to its value on the top of the reservoir as the experiments of Laboureur showed a ratio between 3 and 3.5 relating the measured value on top of the reservoir, and the value interpolated from the curves of van den Berg, as calculated in Table 5.
Table 5 - Ratio between top and side overpressure,

based on Laboureur measurements compared with the curves of van den Berg.

\begin{tabular}{lcc} 
& Test 1 & Test 2 \\
\hline$\Delta \mathrm{P}_{\mathrm{a}}(\mathrm{R}=0.28 \mathrm{~m})$ & 112.6 & 160.9 \\
$\Delta \mathrm{P}_{\mathrm{b}}(\mathrm{R}=0.5 \mathrm{~m})$ & 19.5 & 25.8 \\
$\Delta \mathrm{P}_{\mathrm{c}}(\mathrm{R}=0.28 \mathrm{~m}$ from VDB with $n=1.12)$ & 37.3 & 49.4 \\
$\Delta \mathrm{P}_{\mathrm{c}} / \Delta \mathrm{P}_{\mathrm{a}}$ & 3 & 3.26 \\
\hline
\end{tabular}

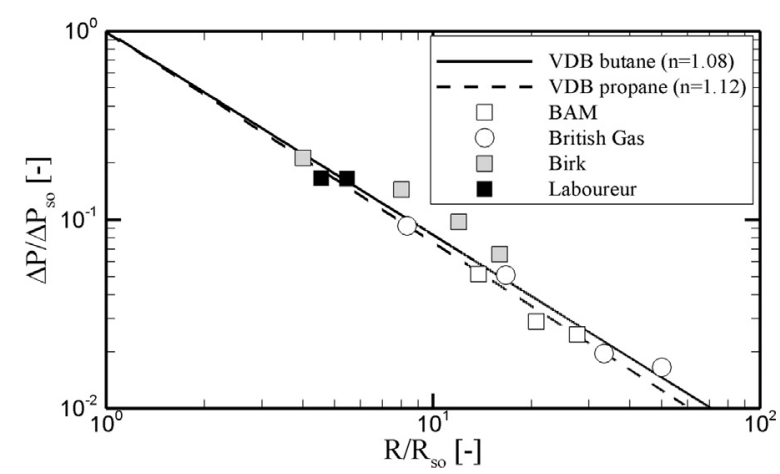

Fig. 16 - Experimental data and van den Berg nondimensionalization compared (side pressure).

\section{Discussion}

The Table 6 allowed to calculate the initial overpressure based on the overpressure measured the closest from the reservoir. But in all the tests, other overpressure measurements were taken further from the reservoir. The Fig. 16 compares the measurements divided by the calculated initial overpressure and radius, as explained in Section 4.3, with the fit of van den Berg curves. The initial overpressure is taken as the initial side overpressure (no factor 3-3.5), since the further positions of overpressure were measured at the side of the reservoir. It can be observed that the comparison is fairly good between the numerical simulation and the data. It can therefore be concluded that, if the initial overpressure and radius are correctly modeled, the simulations of van den Berg can correctly model the overpressure at further distances.

The comparison between the initial shock overpressures calculated from the modeling approach described in Section 3.2 and the measurements scaled using van den Berg is divided in several parts, depending on the rupture conditions; if the reservoir contains separate liquid and vapor phases or a supercritical fluid. For each case, an expansion to $101.3 \mathrm{kPa}$ or an overexpansion to $30 \mathrm{kPa}$ are investigated. Concerning the measurements, the data displayed in Figs. 17 and 18 correspond to the initial overpressure at the top $\left(\Delta P_{\mathrm{s} 0}\right)$, the error bar indicating the range, since the top overpressure is 3-3.5 times the side overpressure. The rupture of a reservoir containing saturated liquid and vapor (rupture before the critical point) is investigated in Fig. 17 left that shows the initial shock overpressure variation with the rupture temperature. The Fig. 17 left shows the experimental results of the British gas performed with butane as fluid, combined with the initial overpressures as calculated by van den Berg from its numerical simulation. The comparison shows that most of the data are fitting well the overexpansion of vapor to $30 \mathrm{kPa}$. But the data related to a reservoir rupture around $100^{\circ} \mathrm{C}$ show a quite large scatter. Among the five data points, the three centered points have similar conditions, but the lower point has a fluid mass halved compared to the other tests and the higher point has a 


\begin{tabular}{|c|c|c|c|c|c|}
\hline & Laboureur & Giesbrecht & BAM & BG & Birk \\
\hline Fluid & Propane & Propylene & Propane & Butane & Propane \\
\hline Tank volume $\left(\mathrm{m}^{3}\right)$ & $95 \times 10^{-6}$ & 1 & 45 & 10.8 & 1.9 \\
\hline Tank D (m) & 0.04 & 0.7 & 2.9 & 1.2 & 1 \\
\hline Mass liquid (kg) & 0.041 & 452 & 3308 & 2083 & 425 \\
\hline Mass vapor (kg) & 0 & 0 & 2252 & 38 & 41 \\
\hline Burst pressure (MPa) & 45 & 6 & 2.5 & 1.51 & 1.9 \\
\hline Liquid $\mathrm{T}\left({ }^{\circ} \mathrm{C}\right)$ & 183 & 70 & 68 & 99.5 & 55 \\
\hline Failure mode & $\begin{array}{l}\text { Machined flaw and } \\
\text { heating }\end{array}$ & $\begin{array}{l}\text { Knife or explosive } \\
\text { charge }\end{array}$ & Fire heating & Explosive & Fire heating \\
\hline Pressure relief valve & No PRV & No PRV & No PRV & No PRV & $\begin{array}{l}\text { PRV operated } \\
\text { several times }\end{array}$ \\
\hline$\Delta P_{\mathrm{a}}(\mathrm{kPa})$ & 161 & 65 & 2.5 & 6.2 & 13.1 \\
\hline$R_{\mathrm{a}}(\mathrm{m})$ & 0.28 (top) & 3.9 (side) & 100 (side) & 25 (side) & 10 (side) \\
\hline$\Delta P_{\mathrm{VDB}}(\mathrm{kPa})$ & & & 3.3 & 10 & 20 \\
\hline$\Delta \mathrm{P}_{\mathrm{s} 0}(\mathrm{kPa})$ at side & 507 & 159 & 48.6 & 66.6 & 61.8 \\
\hline$\Delta P_{\mathrm{s} 0}(\mathrm{kPa})$ at top $\left(\Delta P_{\mathrm{s} 0}\right.$ side $\left.\times 3-3.5\right)$ & 507 & $477-560$ & $146-170$ & $200-233$ & $185-216$ \\
\hline
\end{tabular}

reservoir volume doubled, but with the fluid mass kept similar. Therefore, either the volume taken by the vapor inside the reservoir, not taken into account in this model, influences the results, or this volume change induces a different overexpansion. More data should be needed to confirm these assumptions.

The rupture of a reservoir containing saturated liquid and vapor propane is illustrated in Fig. 17 right. The experimental results of the British gas experiment performed with propane, the BAM experiment, and the experiments of Birk are combined with the initial overpressures as calculated by van den Berg from its 1D numerical simulation. At first, a large discrepancy can be observed between the stronger test and the other tests experienced by Birk. The stronger overpressure has also one of the highest rupture temperature and so pressure, which could explain the discrepancy. When the available energy at rupture is not high enough, a too large part of this energy is needed to open the tank, which decreases the energy of the shock wave. This phenomenon does not concern the tests of British gas since they forced the tank opening with a detonation. If only the stronger test of Birk is taken into account, the data are, similarly to the butane results, fitting better the overexpanded vapor model. Only the BAM test does not fit with the vapor overexpansion line. But the BAM report already states a screening effect of the pieces of the broken reservoir, that weakened the resulting blast wave, so that the overpressure signals recorded were considerably less than expected.

The supercritical ruptures of Laboureur and Giesbrecht are compared in Fig. 18. From this comparison, the supercritical results of Laboureur are well predicted by isentropic expansion to somewhere between 101.3 and $30 \mathrm{kPa}$. In opposite, the single data point for Giesbrecht is completely out of range compared to the model. But the experiments of Giesbrecht have to be taken with great care, since the exact rupture conditions and position of the overpressure measurement are not clearly stated in the publication. Similarly to the comparisons of Fig. 17, more data is needed to confirm this analysis. Finally, the initial radius of the blast as modeled in Section 4.2 is compared with the initial shock radius as observed in the shadowgraph images performed by Laboureur (2012) in Fig. 18 right. This figure shows that the model, whatever the value of the expanded pressure, overestimates the initial radius. But the too small number of data to compare with this model makes its validation difficult.
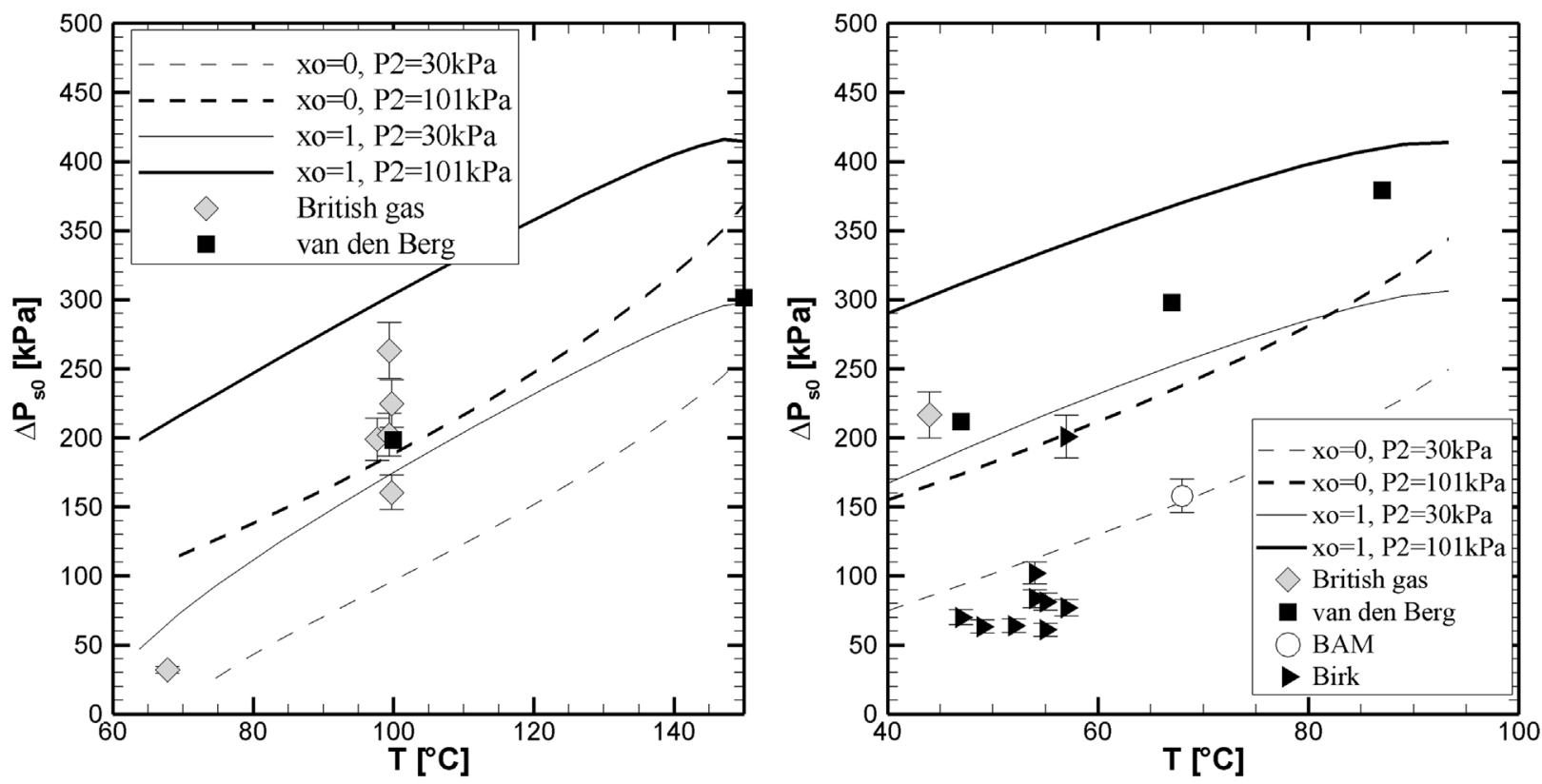

Fig. 17 - Predicted starting shock overpressure versus temperature. Left: saturated butane. Right: saturated propane. 

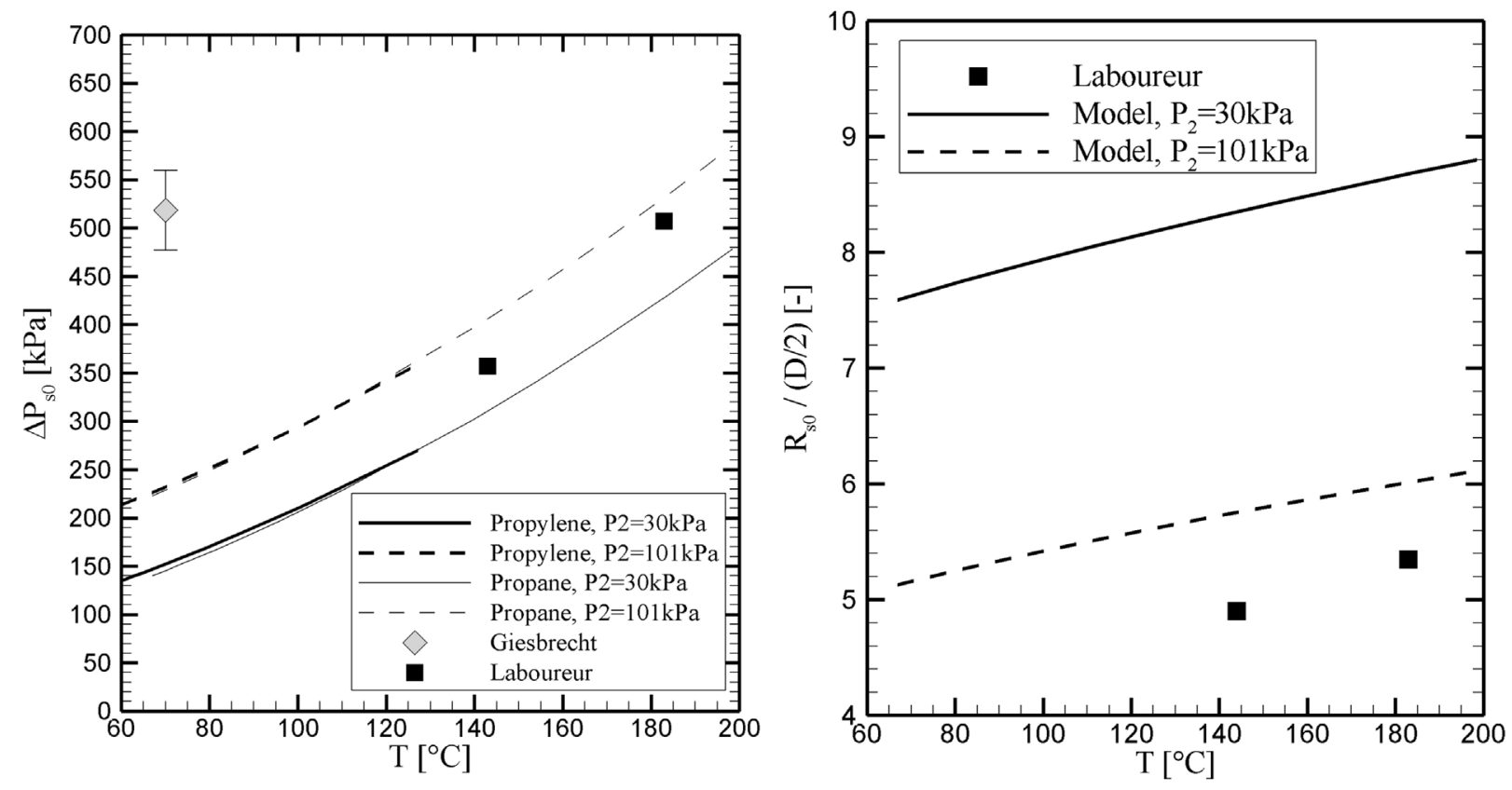

Fig. 18 - Left: predicted starting overpressure versus temperature for supercritical propane and propylene with similar specific volumes as for the experiments. Right: Initial radius of the blast wave calculated from the model, and compared with the experiments of Laboureur.

\section{Conclusions}

In this paper, two types of pressure reservoir ruptures have been experimentally investigated. The mid-scale experiments showed a two-step rupture. At first, the reservoir opens only partially, leading to a stationary shock as the fluid expands to the atmosphere, and then ruptures completely, leading to a moving shock. The supercritical small scale experiments only experienced a one-step rupture and a moving shock. The shadowgraph images showed that the first peak of the measured overpressure is due to the shock that followed the rupture, and that a second shock follows, due to the fast vaporization of the fluid. Both stationary and moving shocks were modeled with basic gas dynamic and thermodynamic principles. However, the lack of measured values in the different steps of the shock formation makes the validation of these models difficult. In addition, the modeling of the moving shock has been used to develop a new modeling approach for the first peak overpressure generated by a BLEVE. The moving shock modeling allows to calculate the overpressure of the starting shock, which, combined with the initial shock radius, is used to calculate the overpressure at other positions, using the numerical simulations of van den Berg, nondimensionalized. This new approach has been compared with five sets of experiments. However there is not enough data available to validate the methods, and the data does not allow to clearly decide if the moving shock comes effectively from the vapor. Therefore, more experimental data is needed. And preferably, these new experiments should use propane, for easier comparison with available data. The tests should be designed with a very rapid and complete failure to fminimize the effect of the rupture on the shock generation. The blast should be measured from the top, the side, and the end of the reservoir, and as close as possible to the reservoir. Preferably, both cases of liquid and vapor and supercritical should be investigated with the same apparatus, and shadowgraph images should be taken to determine the shock starting position.

\section{Acknowledgements}

The authors wish to thank the CEA of Gramat which has supported the experimental results of Laboureur, performed in the frame of a joint research project about source term characterization in major hazards, collaborating with the von Karman Institute and the École des Mines d'Alès.

\section{References}

Abbasi, T., Abbasi, S.A., 2007. The boiling expanding vapour explosion (BLEVE): mechanism, consequence assessment, management. J. Hazard. Mater. 141 (3), 489-519.

Balke, C., et al., 1999. Study of the Failure Limits of a Tank Car Filled with Liquefied Petroleum Gas Subjected to an Open Pool Fire Test. Federal Institute for Materials Research and Testing (BAM), Berlin.

Birk, A.M., Vandersteen, J.D.J., 2006. On the transition from non-BLEVE to BLEVE failure for a $1.8 \mathrm{~m}^{3}$ propane tank. ASME J. Press. Vessel Technol. 128 (4), 648-655.

Birk, A.M., Poirier, D., Davison, C., 2006a. On the thermal rupture of $1.9 \mathrm{~m}^{3}$ propane pressure vessels with defects in their thermal protection system. J. Loss Prev. Process Ind. 19 (6), 582-597.

Birk, A.M., Poirier, D., Davison, C., 2006b. On the response of 500 gal propane tanks to a $25 \%$ engulfing fire. J. Loss Prev. Process Ind. 19 (6), 527-541.

Casal, J., 2008. Evaluation of the Effects and Consequences of Major Accidents in Industrial Plants. Industrial Safety Series, vol. 8. Elsevier, Amsterdam, The Netherlands.

CCPS (Ed.), 1994. Guidelines for Evaluating the Characteristics of Vapor Cloud Explosions, Flash Fires, and BLEVEs. American Institute of Chemical Engineers, New York.

Davison, H., Edwards, M.R., 2008. Effects of fire on small commercial gas cylinders. Eng. Fail. Anal. 15 (8), 1000-1008.

Genova, B., Silvestrini, M., Trujillo, F.J.L., 2008. Evaluation of the blast-wave overpressure and fragments initial velocity for a BLEVE event via empirical correlations derived by a simplified model of released energy. J. Loss Prev. Process Ind. 21 (1), 110-117. 
Giesbrecht, H., et al., 1981. Analysis of explosion hazards on spontaneous release of inflammable gases into the atmosphere. Germ. Chem. Eng. 4, 194-206.

Johnson, D.M., Pritchard, M.J., Wickens, M.J., 1991. A Large Scale Experimental Study of BLEVEs: Contract Report on CEC Co-Funded Research Project. British Gas Plc., Research and Technology Division, Midlands Research Station.

Laboureur, D., 2012. Experimental Characterization and Modeling of Hazards: BLEVE and BOILOVER. Universite Libre de Bruxelles, Brussels.

Laboureur, D., et al., 2013. BLEVE overpressure: multiscale comparison of blast wave modeling. Process Saf. Prog. 33 (3), 274-284, September 2014.

McDevitt, C.A., Steward, F.R., Venart, J.E.S.,1988. Boiling liquid expanding vapour explosion —an update. In: 5th Technical Seminar on Chemical Spills. Pergamon Press, Montreal

McDevitt, C.A., et al., 1990. Initiation step of boiling liquid expanding vapour explosions. J. Hazard. Mater. 25 (1), 169-180.

Rirksomboon, T., 1997. Investigation of Small BLEVE Tests, in Chemical Engineering. National Library of Canada, Ottawa, Canada, pp. 212.
Stawczyk, J., 2003. Experimental evaluation of LPG tank explosion hazards. J. Hazard. Mater. 96 (2), 189-200.

TNO, 1997. Yellow Book: Methods for the Calculation of Physical Effects. CPR 14E, 3rd edition. Committee for the Prevention of Disasters, The Hague.

van den Berg, A.C., 2008. Blast Charts for Explosive Evaporation of Superheated Liquid. Process Saf. Prog. 27 (3), 219-224.

van den Berg, A.C., et al., 2004. Expansion-controlled evaporation: a safe approach to BLEVE blast. J. Loss Prev. Process Ind. 17 (6), 397-405.

van den Berg, A.C., et al., 2006. BLEVE blast by expansion-controlled evaporation. Process Saf. Prog. 25 (1), 44-51.

van der Voort, M.M., et al., 2012. Blast from explosive evaporation of carbon dioxide: experiment, modeling and physics. Shock Waves 22 (2), 129-140.

van der Voort, M.M., et al., 2013. An experimental study on the temperature dependence of $\mathrm{CO}_{2}$ explosive evaporation. J. Loss Prev. Process Ind. 26 (4), 830-838.

White, F.M., 1998. Fluid Mechanics, Fourth edition. WCB McGraw-Hill, New York. 